\title{
Polymorphisms of VKORCI and CYP2C9 are associated with warfarin sensitivity in Chinese population
}

LiQun Jia'

Zanxin Wang ${ }^{1,2}$

Jianlong Men $^{3}$

Heng $\mathrm{Cai}^{4}$

Minxin $\mathrm{Wei}^{2}$

'Department of Cardiovascular Surgery, Tianjin Medical University General Hospital, Tianjin,

${ }^{2}$ Department of Cardiac Surgery, Shenzhen Sun Yat-sen Cardiovascular Hospital, Shenzhen, ${ }^{3}$ Department of Clinical Laboratory, ${ }^{4}$ Department of Cardiology, Tianjin Medical University General Hospital,Tianjin, People's Republic of China
Correspondence: Zanxin Wang

Department of Cardiac Surgery, Shenzhen Sun Yat-sen Cardiovascular Hospital, \#I02I Dongmen North Road, Luohu District, Shenzhen 518II2, Guangdong Province, People's Republic of China

Email zanxinwang@।26.com
This article was published in the following Dove Press journal:

Therapeutics and Clinical Risk Management

31 March 2017

Number of times this article has been viewed

Objective: Warfarin is a commonly prescribed anticoagulant for prevention of thromboembolic events. Wide inter-individual dose variation, narrow therapeutic range and risk of serious bleeding result in difficulties in achieving the therapeutic effect. The present study was designed to clarify the real biological significance of the polymorphisms of VKORC1 and cytochrome P450 2C9 (CYP2C9) in warfarin metabolism.

Methods: A total of 214 patients with warfarin anticoagulant therapy were selected. During follow-up of anticoagulation, warfarin dosage and associated international normalized ratio values were recorded. Genetic polymorphisms of VKORC1 promoter and from exon 1 to exon 3 and CYP2C9 exon 4 sequence were detected by polymerase chain reaction and gene sequencing.

Results: Five polymorphisms were identified in this research, which were VKORC1 1173C $>$ T (intron 1), 1542G $>\mathrm{C}$ (intron 2), 2255C $>\mathrm{T}$ (intron 2), 3730C $>\mathrm{T}$ ( $3^{\prime}$-downstream) and CYP2C9 exon $4-65 \mathrm{G}>\mathrm{C}$. VKORC1 1173CT, 1542GC, 2255CT and 3730CT polymorphisms were detected in same patients, but CYP2C9 exon 4-65GC carriers were different from them. VKORC1 1173CT, 1542GC, 2255CT, 3730CT carriers and CYP2C9 exon 4-65GC carriers had significantly higher warfarin daily dosage than others ( $3.2 \pm 0.6$ vs $3.1 \pm 1.1 \mathrm{vs} 2.6 \pm 0.8 \mathrm{mg} /$ day). Logistic regression analysis revealed VKORC1 1173CT, 1542GC, 2255CT, 3730CT carrier status (odds ratio $[\mathrm{OR}]=3.233,95 \%$ confidence interval $[\mathrm{CI}]: 1.259-8.303, P=0.015$ ) and obesity with body mass index $>27 \mathrm{~kg} / \mathrm{m}^{2}(\mathrm{OR}=1.223,95 \% \mathrm{CI}: 1.097-1.363, P<0.001)$ to have independent and statistically significant contributions to high warfarin dosage.

Conclusion: In general, in VKORC1 1173CT, 1542GC, 2255CT and 3730CT carriers and in obese patients, warfarin maintenance doses were significantly higher than in the others.

Keywords: warfarin, vitamin $\mathrm{K}$, cytochrome $\mathrm{P} 450$, polymorphism

\section{Introduction}

Warfarin is the most commonly used oral anticoagulant drug in the prevention of thromboembolism. For patients with prosthetic heart valve replacement, the incidence of hemorrhage is inversely connected with the efficacy of anticoagulation and appears to be a major risk indicator for bleeding complications. ${ }^{1,2}$ It has been reported that the Chinese populations are more sensitive to warfarin than western populations. ${ }^{1,3}$ To maintain the international normalized ratio (INR) of 2.0-3.0, the mean daily warfarin dosage is lower in Chinese than in Caucasians. This cannot be explained simply by a lower mean body weight among the Chinese. ${ }^{3}$

The vitamin $\mathrm{K}$ epoxide reductase complex 1 (VKORC1) recycles vitamin $\mathrm{K}$ 2, 3-epoxide back to active vitamin $\mathrm{K}$ hydroquinone, an important cofactor involved 
in the activation of vitamin K-dependent clotting factors. VKORC1 is the target enzyme of inhibition of warfarin, ${ }^{4,5}$ and variants of the VKORC1 gene are known to be associated with warfarin resistance. Four different exonic mutations have been described in individuals with known warfarin resistance phenotype. ${ }^{6}$ It was notable that these mutations clustered in the luminal loops of the gene and were predicted to have functional effects. ${ }^{7}$ More recently, VKORC1 promoter polymorphisms that occur frequently have been discovered. They exhibit linkage disequilibrium, and are associated with higher warfarin dose requirements. ${ }^{8-10}$

Cytochrome P450 2C9 (CYP2C9) is polymorphic in human and is principally responsible for the metabolism of warfarin. Six distinct single-base pair substitution polymorphisms of the CYP2C9 gene have been discovered and are designated $* 1$ through $* 6 .^{11,12}$ However, known CYP2C9 polymorphisms cannot entirely account for the low-dose requirement of warfarin seen in Chinese patients with mitral valve replacement.

Collectively, genetic polymorphisms are involved in both pharmacodynamic (VKORC1) and pharmacokinetic (CYP2C9) factors. They appear to interplay in the overall inter-individual variability of warfarin doses. In this context, we screened the promoter and the whole exons (exon 1 to 3 ) of VKORC1 and CYP2C9 exon 4 polymorphisms and investigated their roles in warfarin sensitivity in Chinese population.

\section{Patients and methods}

A total of 214 patients with warfarin anticoagulant therapy were selected. Average age was $62.1 \pm 10.5$ years. They were receiving maintenance warfarin therapy with a stable, therapeutic INR between 2 and 2.5 for at least 3 weeks. Mean daily warfarin requirement was from 1.250 to $5.077 \mathrm{mg} /$ day. Standard clinical laboratory tests indicated that all of the patients had normal liver function and renal function. Patients with concurrent medications with potential to affect warfarin's metabolism included amiodarone, non-steroidal anti-inflammatory drugs, cimetidine, thyroid hormone, or carbamazepine were excluded. The study was approved by the Ethics Committee of Tianjin Medical University General Hospital and Shenzhen Sun Yat-sen Cardiovascular Hospital. Written informed consent was obtained from each patient.

\section{Study protocol}

Blood (5-10 mL) was obtained from 12 to $16 \mathrm{~h}$ after administration of the last dose of warfarin during a routine clinic visit. The average daily dose of warfarin was calculated from 1-week period, and latest INR was recorded.

\section{Genotyping protocol}

DNA was extracted with Gentra DNA Isolation Kit (Hilden, Germany). Sequence amplification was performed by polymerase chain reaction. Gene sequencing of VKORC1 promoter and exon 1 to exon 3 and CYP2C9 exon 4 was performed following methodology described previously. $^{8}$

\section{Statistical analysis}

Statistical analysis was performed using Statistical Package for the Social Sciences (SPSS) for Windows (version 15.0). Continuous data are presented as mean \pm standard deviation and analyzed using independent-samples $t$-test, repeated measures analysis of variance (ANOVA), or one-way ANOVA, as appropriate. Categorical variables were expressed as frequencies and analyzed with $\chi^{2}$ test. Logistic regression was used to analyze the risk factors of outcome. $P$-values $<0.05$ were considered statistically significant.

\section{Results}

Average body mass index (BMI) of the 214 participants was $24.7 \pm 3.8 \mathrm{~kg} / \mathrm{m}^{2}$. Mean daily warfarin requirement was from 1.250 to $5.077 \mathrm{mg} /$ day when therapeutic INR (2.0-2.5) levels were maintained. Patient demographics are presented in Table 1.

Five polymorphisms were identified in this study. They were VKORC1 1173C $>$ T, 1542G $>$ C, 2255C $>$ T, 3730C $>$ T and CYP2C9 exon $4-65 \mathrm{G}>\mathrm{C}$. Genotype distributions of all polymorphisms were in Hardy-Weinberg equilibrium. These genotype frequencies are shown in Table 2. VKORC1 $1173 \mathrm{CT}, 1542 \mathrm{GC}, 2255 \mathrm{CT}$ and 3730CT carrier status was in the same patients, and CYP2C9 exon 4-65GC carriers

Table I Patient characteristics

\begin{tabular}{|c|c|}
\hline Parameters & Data \\
\hline $\operatorname{Sex}(M / F)$ & $111 / 103$ \\
\hline Age (years) & $58.8 \pm 10.9$ \\
\hline BMI $\left(\mathrm{kg} / \mathrm{m}^{2}\right)$ & $24.1 \pm 3.5$ \\
\hline Smoking (n, \%) & $73(34.3 \%)$ \\
\hline Alcohol drinking (n, \%) & $29(13.7 \%)$ \\
\hline Diabetes mellitus (n, \%) & $25(11.8 \%)$ \\
\hline \multicolumn{2}{|l|}{ Kinds of disease } \\
\hline Atrial fibrillation (n, \%) & $74(34.6 \%)$ \\
\hline $\operatorname{AVR}(n, \%)$ & $59(27.6 \%)$ \\
\hline MVR (n, \%) & $29(13.6 \%)$ \\
\hline$A V R+M V R(n, \%)$ & $27(12.6 \%)$ \\
\hline MVR + CABG (n, \%) & $25(\mathrm{I} 1.6 \%)$ \\
\hline
\end{tabular}

Note: Data are presented as either mean \pm SD or counts.

Abbreviations: M, male; F, female; BMI, body mass index; AVR, aortic valve replacement; MVR, mitral valve replacement; CABG, coronary artery bypass grafting; SD, standard deviation. 
Table 2 Genotype distributions

\begin{tabular}{|c|c|c|c|c|c|c|}
\hline \multirow{2}{*}{$\begin{array}{l}\text { Polymorphisms } \\
\text { VKORCI }\end{array}$} & \multicolumn{3}{|c|}{ Genotype } & \multicolumn{2}{|l|}{ Allele } & \multirow{2}{*}{$\frac{P \text {-value }}{0.270}$} \\
\hline & TT(I84) & СТ(30) & $\mathrm{CC}(0)$ & $\mathrm{T}(398)$ & $C(30)$ & \\
\hline \multicolumn{7}{|l|}{$1173 C>T$} \\
\hline VKORCI & $\mathrm{CC}(184)$ & $C G(30)$ & $\mathrm{GG}(0)$ & $C(398)$ & $G(30)$ & 0.270 \\
\hline \multicolumn{7}{|l|}{$1542 \mathrm{G}>\mathrm{C}$} \\
\hline VKORCI & TT(184) & $\mathrm{CT}(30)$ & $\mathrm{TT}(0)$ & $\mathrm{T}(398)$ & $C(30)$ & 0.270 \\
\hline \multicolumn{7}{|l|}{$2255 C>T$} \\
\hline VKORCI & GG(I84) & $\mathrm{GA}(30)$ & $\mathrm{AA}(0)$ & $G(398)$ & $A(30)$ & 0.270 \\
\hline \multicolumn{7}{|l|}{$3730 \mathrm{C}>\mathrm{T}$} \\
\hline CYP2C9 exon 4 & GG(193) & $G C(2 I)$ & $\mathrm{CC}(0)$ & $\mathrm{G}(407)$ & $C(2 I)$ & 0.450 \\
\hline$-65 G>C$ & & & & & & \\
\hline
\end{tabular}

Note: Data in parentheses are numbers of each genotype.

were absolutely different from them. The clinical characteristics of the VKORC1 1173CT, 1542GC, 2255CT, 3730CT carriers, CYP2C9 exon 4-65GC carriers and the others are exhibited in Table 3. These patient groups did not differ significantly in relation to other parameters. However, VKORC1 1173CT, 1542GC, 2255CT, 3730CT carriers and CYP2C9 exon 4-65GC carriers had significantly higher daily warfarin dosage than the others $(3.2 \pm 0.6$ vs $3.1 \pm 1.1$ vs $2.6 \pm 0.8 \mathrm{mg} /$ day) (Figure 1).

Logistic regression analysis included age, sex, BMI and carrier statuses as covariates and showed that VKORC1 $1173 \mathrm{CT}, 1542 \mathrm{GC}, 2255 \mathrm{CT}, 3730 \mathrm{CT}$ carriers (odds ratio $[\mathrm{OR}]=3.233,95 \%$ confidence interval $[\mathrm{CI}]: 1.259-8.303$, $P=0.015$ ) and obese individuals (with BMI $>27 \mathrm{~kg} / \mathrm{m}^{2}$ ) (OR $=1.223$, 95\% CI: 1.097-1.363, $P<0.001)$ had independent and statistically significant contributions to high warfarin dosage (Table 4).

\section{Discussion}

Warfarin's anticoagulant activity results from inhibition of hepatic vitamin $\mathrm{K}$ epoxide reductase that affects the synthesis of various coagulation factors. Recently, variants of the VKORC1 have been described to have potentially functional consequences. ${ }^{13-15}$ However, these polymorphic variants are not useful for testing in Chinese population because of their low prevalence. In the present research, all exons of VKORC1 (exon 1-exon 3) and the promoter were examined by gene sequencing. Four polymorphisms were identified, which were $1173 \mathrm{C}>\mathrm{T}, 1542 \mathrm{G}>\mathrm{C}, 2255 \mathrm{C}>\mathrm{T}$, $3730 \mathrm{C}>\mathrm{T}$. The results indicated that polymorphisms are found in absolute linkage disequilibrium since $1173 \mathrm{CT}$, $1542 \mathrm{GC}, 2255 \mathrm{CT}, 3730 \mathrm{CT}$ are carried by same patients. VKORC1 1173CT could be used as the tagging SNP to represent the others for further research. Logistic analysis showed that $1173 \mathrm{CT}, 1542 \mathrm{GC}, 2255 \mathrm{CT}, 3730 \mathrm{CT}$ were one of the independent contributions of high warfarin dosage. This is consistent with previously published report, which indicates that $1173 \mathrm{CT}$ was associated with lower VKORC1 mRNA levels in human liver. ${ }^{16}$ This finding suggests that $1173 \mathrm{CT}$ may be associated with the lower levels of reduced form of vitamin $\mathrm{K}$, thereby making patients with this variant more susceptible to the anticoagulation effect of warfarin.

Importantly, VKORC1 $1173 \mathrm{C}>\mathrm{T}$ genotypes are significantly different among Asians, Caucasians and African Americans. The frequencies of VKORC1 1173C allele in Asians, Caucasians and African Americans were 11\%, 58\% and $91 \%$, respectively. ${ }^{17-19}$ In the present result, the frequency of $1173 \mathrm{CT}$ is approximately $14 \%$. Furthermore, multiple regression analysis showed that the VKORC1 $1173 \mathrm{C}>\mathrm{T}$ variant was an important covariate with respect to the interindividual variability in warfarin dosage. Patients carrying the $\mathrm{C}$ allele at the position of 1173 of the $V K O R C 1$ gene are associated with a significantly higher dose requirement of warfarin. So, these results suggest that the lower dose requirements in Chinese population may possibly reflect the lower frequency of the VKORC1 $1173 \mathrm{C}$ allele compared to western population.

Table 3 Clinical characteristics in three groups of genotypes

\begin{tabular}{|c|c|c|c|c|}
\hline Parameters & $\begin{array}{l}\text { VKORCI II I3CT, } \\
\text { I542GC, 2255CT, } \\
3730 C T \text { carriers }(n=30)\end{array}$ & $\begin{array}{l}\text { CYP2C9 } \\
\text { exon } 4-65 G C \\
\text { carriers }(n=2 I)\end{array}$ & $\begin{array}{l}\text { Others } \\
(n=163)\end{array}$ & $P$-value \\
\hline $\operatorname{Sex}(M / F)$ & $16 / 14$ & $7 / 14$ & $88 / 75$ & 0.344 \\
\hline Age (years) & $56.4 \pm 8.1$ & $56.2 \pm 16.7$ & $59.5 \pm 10.5$ & 0.294 \\
\hline BMI $\left(k g / m^{2}\right)$ & $24.5 \pm 3.1$ & $25.2 \pm 5.0$ & $24.0 \pm 3.4$ & 0.423 \\
\hline Smoking (n, \%) & $10(33 \%)$ & $5(25 \%)$ & $58(36 \%)$ & 0.523 \\
\hline Alcohol drinking (n, \%) & $4(14 \%)$ & $4(17 \%)$ & 21 (13\%) & $0.87 I$ \\
\hline Diabetes mellitus ( $\mathrm{n}, \%)$ & $4(14 \%)$ & $2(8 \%)$ & $19(12)$ & 0.512 \\
\hline
\end{tabular}

Note: Data are presented as either mean \pm SD or counts.

Abbreviations: M, male; F, female; BMI, body mass index; SD, standard deviation. 


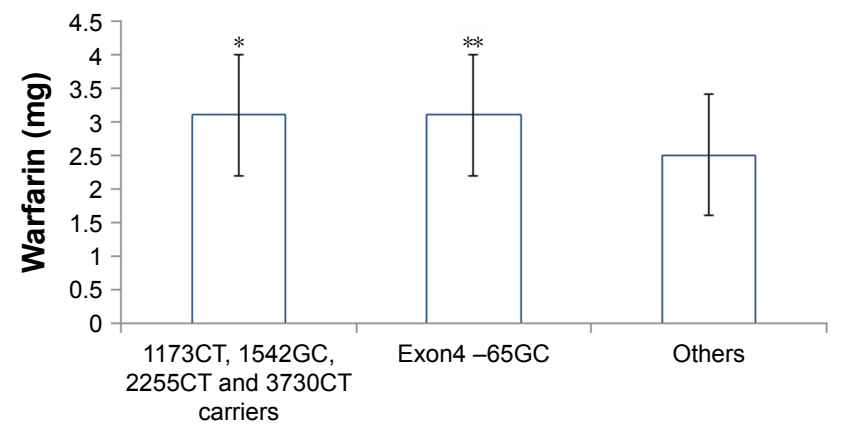

Figure I Warfarin dosages in different genotypes.

Notes: Data are presented as mean \pm standard deviation. *Compared to others, $P=0.012$, ***ompared to others, $P=0.034$.

The other genotypic polymorphism investigated in this research is CYP2C9 exon 4-65G $>$ C. Our results revealed that $-65 \mathrm{C}$ allele appeared to be more significant in patients who were given higher warfarin maintenance dose. Despite the fact that the real function of this novel CYP2C9 polymorphic allele in relation to warfarin metabolism is still unclear, it is possible that the $-65 \mathrm{C}$ allele affects some important phases in catalytic activity of warfarin that leads to this effect. However, in the multiple regression analysis, presence of CYP2C9 exon $4-65 \mathrm{G}>\mathrm{C}$ did not have any effect on high warfarin dosage when the influence of VKORC1 genotype on the interindividual variability in warfarin doses was controlled.

BMI $>27 \mathrm{~kg} / \mathrm{m}^{2}$, which is the Chinese standard for obesity, was the other independent risk factor for high warfarin dosage in the present research. This suggests that obese patients should be considered with higher dose of warfarin to maintain the target INR level. Furthermore, as Chinese population has lower level of BMI than western people, ${ }^{20}$ the daily requirement of warfarin is also lower. This may be another reason to explain that Chinese population in general is more sensitive to warfarin.

\section{Limitations}

Our study has some limitations. Only the CYP2C9 exon 4 DNA sequence was analyzed in the current study. Genetic polymorphism at other loci may be undetected. Further

Table 4 Logistic regression for patients' covariates that are associated with high warfarin doses

\begin{tabular}{|c|c|c|}
\hline Covariates & OR $(95 \% \mathrm{CI})$ & $P$-value \\
\hline Sex, male & $1.866(0.947-3.677)$ & 0.072 \\
\hline Age & $1.001(0.97 I-1.032)$ & 0.927 \\
\hline $\mathrm{BMI}>27 \mathrm{~kg} / \mathrm{m}^{2}$ & $1.223(1.097-1.363)$ & $<0.001$ \\
\hline $\begin{array}{l}\text { VKORCI II73CT, I542GC, } \\
2255 C T, 3730 C T \text { carriers }\end{array}$ & $3.233(1.259-8.303)$ & 0.015 \\
\hline CYP2C9 exon 4-65GC carrier & $2.433(0.830-7.131)$ & 0.105 \\
\hline
\end{tabular}

Abbreviations: $\mathrm{OR}$, odds ratio; $\mathrm{Cl}$, confidence interval; $\mathrm{BMI}$, body mass index. investigation is necessary to investigate the clinical impact of genetic variance of CYP2C9 on warfarin management. In addition, warfarin patients usually visit the clinic every 3-6 months depending on their INR levels. We included only patients into the study if they could return to the clinic for INR testing and warfarin dose follow-up. This led to the relative small sample size of the study.

\section{Conclusion}

The warfarin maintenance doses of VKORC1 1173CT, $1542 \mathrm{GC}, 2255 \mathrm{CT}$ and $3730 \mathrm{CT}$ carriers and in obese patients were significantly higher than in the others. Our results indicate that the ethnic origin of the warfarin-treated population must be considered as an influencing factor affecting the dose response. In Chinese population, both obesity and the genetic polymorphism of genes affecting the warfarin metabolism seem to affect considerably the clinical response to warfarin.

\section{Acknowledgments}

This research was funded by National Natural Science Foundation of China (81600208), Tianjin Municipal Health Bureau (2013KZ122), Tianjin Municipal Science and Technology Commission (14ZCZDSY00023) and The Project Sponsored by the Scientific Research Foundation for the Returned Overseas Chinese Scholars, Tianjin, People's Republic of China.

\section{Disclosure}

The authors report no conflicts of interest in this work.

\section{References}

1. Rowe AS, Mahbubani PS, Bucklin MH, Clark CT, Hamilton LA. Activated prothrombin complex concentrate versus plasma for reversal of warfarin-associated hemorrhage. Pharmacotherapy. 2016;36(11): $1132-1137$.

2. Marino KK, Santiago RA, Dew RB 3rd, et al. Management of dabigatranassociated bleeding with two doses of idarucizumab plus hemodialysis. Pharmacotherapy. 2016;36(10):e160-e165.

3. Yu HC, Chan TY, Critchley JA, Woo KS. Factors determining the maintenance dose of warfarin in Chinese patients. QJM. 1996;89(2): $127-135$.

4. Li T, Chang CY, Jin DY, Lin PJ, Khvorova A, Stafford DW. Identification of the gene for vitamin K epoxide reductase. Nature. 2004;427(6974): $541-544$

5. Obeng AO, Kaszemacher T, Abul-Husn NS, et al. Implementing algorithmguided warfarin dosing in an ethnically diverse patient population using electronic health records and preemptive CYP2C9 and VKORC1 genetic testing. Clin Pharmacol Ther. 2016;100(5):427-430.

6. Rost S, Fregin A, Ivaskevicius V, et al. Mutations in VKORC1 cause warfarin resistance and multiple coagulation factor deficiency type 2. Nature. 2004;427(6974):537-541.

7. Goodstadt L, Ponting CP. Vitamin K epoxide reductase: homology, active site and catalytic mechanism. Trends Biochem Sci. 2004;29(6): 289-292. 
8. Bodin L, Verstuyft C, Tregouet DA, et al. Cytochrome P450 2C9 (CYP2C9) and vitamin $\mathrm{K}$ epoxide reductase (VKORC1) genotypes as determinants of acenocoumarol sensitivity. Blood. 2005;106(1): $135-140$.

9. Rieder MJ, Reiner AP, Gage BF, et al. Effect of VKORC1 haplotypes on transcriptional regulation and warfarin dose. $N$ Engl J Med. 2005; 352(22):2285-2293.

10. Yuan HY, Chen JJ, Lee MM, et al. A novel functional VKORC1 promoter polymorphism is associated with inter-individual and interethnic differences in warfarin sensitivity. Hum Mol Genet. 2005; 14(13):1745-1751.

11. Sullivan-Klose TH, Ghanayem BI, Bell DA, et al. The role of the CYP2C9-Leu359 allelic variant in the tolbutamide polymorphism. Pharmacogenetics. 1996;6(4):341-349.

12. Stubbins MJ, Harries LW, Smith G, Tarbit MH, Wolf CR. Genetic analysis of the human cytochrome P450 CYP2C9 locus. Pharmacogenetics. 1996;6(5):429-439.

13. D'Andrea G, D'Ambrosio RL, Di Perna P, et al. A polymorphism in the VKORC1 gene is associated with an interindividual variability in the dose-anticoagulant effect of warfarin. Blood. 2005;105(2): 645-649.

14. Hart R, Veenstra DL, Boudreau DM, Roth JA. Impact of body mass index and genetics on warfarin major bleeding outcomes in a community setting. Am J Med. 2016;130(2):222-228.
15. Johnson JA, Gong L, Whirl-Carrillo M, et al; Clinical Pharmacogenetics Implementation Consortium. Clinical Pharmacogenetics Implementation Consortium Guidelines for CYP2C9 and VKORC1 genotypes and warfarin dosing. Clin Pharmacol Ther. 2011;90(4):625-629.

16. Takahashi H, Wilkinson GR, Nutescu EA, et al. Different contributions of polymorphisms in VKORC1 and CYP2C9 to intra- and interpopulation differences in maintenance dose of warfarin in Japanese, Caucasians and African-Americans. Pharmacogenet Genomics. 2006; 16(2):101-110.

17. Moon HW, Noh J, Yun YM, et al. The effect of CYP2C9, VKORC1 genotypes and old age on warfarin pharmacologic sensitivity in Korean patients with thromboembolic disease. Ann Clin Lab Sci. 2011;41(3):229-235.

18. Verstuyft C, Delavenne X, Rousseau A, et al. A pharmacokineticpharmacodynamic model for predicting the impact of CYP2C9 and VKORC1 polymorphisms on fluindione and acenocoumarol during induction therapy. Clin Pharmacokinet. 2012;51(1):41-53.

19. Kovac MK, Maslac AR, Rakicevic LB, Radojkovic DP. The c. $-1639 \mathrm{G}>\mathrm{A}$ polymorphism of the VKORC1 gene in Serbian population: retrospective study of the variability in response to oral anticoagulant therapy. Blood Coagul Fibrinolysis. 2010;21(6):558-563.

20. Zheng W, McLerran DF, Rolland B, et al. Association between bodymass index and risk of death in more than 1 million Asians. $N$ Engl J Med. 2011;364(8):719-729.
Therapeutics and Clinical Risk Management

\section{Publish your work in this journal}

Therapeutics and Clinical Risk Management is an international, peerreviewed journal of clinical therapeutics and risk management, focusing on concise rapid reporting of clinical studies in all therapeutic areas, outcomes, safety, and programs for the effective, safe, and sustained use of medicines. This journal is indexed on PubMed Central, CAS,

\section{Dovepress}

EMBase, Scopus and the Elsevier Bibliographic databases. The manuscript management system is completely online and includes a very quick and fair peer-review system, which is all easy to use. Visit http://www.dovepress.com/testimonials.php to read real quotes from published authors.

Submit your manuscript here: http://www.dovepress.com/therapeutics-and-clinical-risk-management-journal 